\title{
AKUISISI DATA MENGGUNAKAN LABVIEW DENGAN ARDUINO SEBAGAI PERANGKAT KERAS BERBIAYA RENDAH
}

\author{
Dadan Nurdin Bagenda, Paula Santi Rudati \\ Program Studi D-III Teknik Elektronika, Jurusan Teknik Elektro, Politeknik Negeri Bandung \\ Jl. Kampus Polban Ds. Ciwaruga, Bandung, Indonesia 40012.
}

\begin{abstract}
Industrial and academic laboratories cannot be separated from the use of DAQ, most of industrial automation generally requires massive amounts of DAQ and high speed. DAQ LabView software provides various facilities so that projects can be faster. Honestly, the price of hardware for DAQ is relatively expensive, luckily LabView give the opportunity to support ability many hardware including Arduino Board. Using the LINX library from Makerhub are free, so that the DAQ Practicum as industry standard can be done by affordable prices. The results without Linx, the average travel time for serial deliveries is 5.98 us/byte at 2Mbps. With Linx, "loop rate $(\mathrm{Hz})$ " feature is valid as a 2-time (trigger-echo) measurement, and the data transmission time is below $20.41 \mathrm{~ms}$, the digital DAQ of 2-way by (trigger-echo) is 20.41, also flip-flop transmission has an average time $13.7 \mathrm{~ms} / \mathrm{loop}$, also analog DAQ from LM35 have average time $7.87 \mathrm{~ms} / \mathrm{loop}$.
\end{abstract}

Keywords: Low Price DAQ; LabView; LINX; Arduino DAQ

\section{PENDAHULUAN}

Masyarakat industri, para peneliti dan mahasiswa teknik di laboratorium tak lepas dari penggunaan data akusisi, baik itu dalam jumlah data sedikit maupun dalam jumlah banyak, terutama industri umumnya memerlukan data akusisi dalam jumlah masif dan kecepatan yang tinggi.

Software DAQ labView sudah umum digunakan di laboratorium juga di industri sebagai software pengembang aplikasi akuisisi data, pemantauan juga kontroler yang menyediakan berbagai kemudahan sehingga projek bisa lebih cepat diselesaikan dibandingkan pengembang aplikasi klasik.

Sayangnya harga perangkat keras untuk akuisisi data yang berpasangan dengan LabView relatif bernilai tinggi (i.e. National Instrument) sehingga banyak sekolah dan perguruan tinggi jurusan teknik yang tidak mampu memilikinya.

Beruntungnya software LabView membuka kesempatan untuk terintegrasi (melalui protokol komunikasi klasik) dengan banyak perangkat keras termasuk Arduino, bahkan sudah beredar library Labview Interface For Arduino (LVIFA base) secara gratis, sehingga Praktikum DAQ mendekati standar industri bisa dilakukan dengan harga terjangkau. Saat ini LVIFA base telah dikembangkan menjadi LINX dari markerhub[1].

Walaupun pengujian kecepatan Arduino Uno sudah ada secara embedded dan komunikasi sederhana [2], namun perlu diuji seberapa cepat data yang dapat diakuisisi oleh Arduino menggunakan LabView, penelitian ini akan melakukan pengujian menggunakan Arduino Uno yang mengirimkan data dari sensor LM35.

Berdasarkan latar belakang di atas, maka masalahnya dapat dirumuskan sebagai berikut:

- Perangkat keras akuisisi data yang ada relatif mahal, sehingga sehingga banyak sekolah dan perguruan tinggi jurusan teknik yang tidak mampu memilikinya.

- Kecepatan akuisi data Labview melalui perangkat keras Arduino masih diragukan, karena belum ada pembahasan khusus terkait ini.

- Belum ada pembahasan khusus perbedaaan kecepatan menggunakan Arduino Uno sebagai perangkat keras akuisisi data di Labview.

Berdasarkan permasalahan tersebut di atas maka ruang lingkup bahasan makalah ini meliputi :

- Metodologi yang digunakan adalah kuantitatif experimental.

- Pengujian dilakukan pada perangkat keras Arduino Uno.

- Digital dan Sensor LM35.

Tujuan dari penelitian ini adalah membuat sistem pengujian lilitan benang yang mempunyai fitur sebagai berikut:

- Membuka alternatif hardware akuisisi data menggunakan Arduino sebagai pasangan software LabView.

- Mengukur seberapa cepat akuisi data melalui perangkat keras Arduino Uno.

- Membandingkan seberapa jauh perbedaaan penggunaan Arduino Uno sebagai perangkat keras akuisisi data.

\section{METODE PENELITIAN Tinjauan Pustaka}

Penelitian lain memicu gagasan penelitian ini, dengan ringkasan yang disusun dalam bentuk table, seperti pada Tabel 1. Tabel ini juga bisa mewakili penelitan apa saja yang dijadikan referensi dan menunjukan pada ranah apa kaitannya dengan penelitian ini. Tabel ini pun menunjukan perbedaan 
variabel penelitian referensi dan penelitian yang diusulkan.

Tabel 1. Ranah Tinjauan Pustaka

\begin{tabular}{|c|c|c|c|c|}
\hline No & $\begin{array}{l}\text { Karya } \\
\text { Ilmiah }\end{array}$ & $\begin{array}{c}\text { Lab } \\
\text { Vie } \\
\text { w }\end{array}$ & $\begin{array}{c}\text { Comm } \\
\text { DaQ }\end{array}$ & $\begin{array}{l}\text { Speed } \\
\text { revie } \\
\text { w }\end{array}$ \\
\hline [2] & $\begin{array}{l}\text { Bagenda \& } \\
\text { Hudaya, } \\
2016\end{array}$ & $\mathrm{X}$ & $\begin{array}{c}\text { Dummy } \\
\text { data }\end{array}$ & $\sqrt{ }$ \\
\hline [3] & $\begin{array}{l}\text { R \& } \\
\text { Krishna, } \\
2013\end{array}$ & $\sqrt{ }$ & $\begin{array}{l}\text { (analog) } \\
\text { IRProx., } \\
\text { Varistor }\end{array}$ & $\sqrt{ }$ \\
\hline [4] & $\begin{array}{l}\text { Kanani \& } \\
\text { Thakker, } \\
2015\end{array}$ & $\sqrt{ }$ & $\begin{array}{c}\text { (1 wire } \\
\text { serial) } \\
\text { DHT11, } \\
\text { (analog) } \\
\text { LDR, HC- } \\
\text { SR04 }\end{array}$ & $X$ \\
\hline \multirow[t]{2}{*}{ [5] } & $\begin{array}{l}\text { Hammoumi, } \\
\text { Motahhir, } \\
\text { Chalh, El } \\
\text { Ghzizal, \& } \\
\text { Derouich, } \\
2018\end{array}$ & $\sqrt{ }$ & $\begin{array}{l}\text { (analog) } \\
\text { INA169 } \\
\text { current } \\
\text { sensor, }\end{array}$ & $\sqrt{ }$ \\
\hline & $\begin{array}{l}\text { Penelitian } \\
\text { ini, }\end{array}$ & $\sqrt{ }$ & $\begin{array}{l}\text { Digital, } \\
\text { Analog } \\
\text { (LM35) }\end{array}$ & $\sqrt{ }$ \\
\hline
\end{tabular}

\section{Literatur Review}

Arduino sudah mulai digunakan dalam akuisisi data, terlihat dengan tersedianya Lab View Interface for Arduino (LVIFA). Bentuk modul ini compact dan IDE-nya user friendly, namun pemrogramannya bahasa $\mathrm{C}$ dimana salahsatu contohnya lebih sulit dalam manajemen register dibandingkan assembler, juga hasil level optimasi default compiler-nya relatif lambat, hal ini dapat berdampak memperlambat eksekusi. [2]

Input analog Arduino Uno hanya 10-bit dan perkiraan terbaik pengujian dari laju sampel sekitar 100 sampel per detik, pembaca dapat melakukan lebih cepat dari ini jika menyimpan sementara data dalam memori Arduino dan kemudian mengirimkannya ke komputer perbagian. Perlu diingat bahwa harga Arduino Uno hanya 30 USD dibandingkan dengan Industrial DaQ > \$200 untuk USB-600x (dan dalam contoh tugas DAQ referensi, dia hanya perlu 1 sampel setiap 10 detik), dari pengujiannya teangan berhasil terbaca dan dikirim setiap 100ms [3].

$$
\text { LABVIEW (Laboratory Virtual }
$$

Instrumentation Engineering Workbench) adalah perangkat lunak yang menyediakan instrumentasi virtual. Pada Penelitian ini LABVIEW digunakan untuk mengembangkan antarmuka pengguna grafis untuk menampilkan parameter yang diukur. Ini memiliki pengkodean dalam bentuk diagram blok sehingga sangat mudah digunakan dan memberikan solusi terbaik. LabView Interface For Arduino (LIFA) adalah library bagi LabView agar mempermudah penggunaan Arduino sebagai perangkat keras akuisisi data. [4]

Terdapat beberapa alasan utama LabVIEW membuat kita lebih produktif saat menggunakan Arduino, diantaranya: [3]

- Tersedia Grafik User Interface (GUI) sebagai interaksi antara kita dengan sistem.

- Mengoptimalkan proses desain kita dengan pemrograman grafis yang intuitif.

- Meningkatkan pengalaman debug kita dengan fitur interaktif.

- Bisa memanfaatkan fungsi bawaan untuk mengimplementasikan algoritma yang sederhana sampai rumit.

- Terbukanya Application Programming Interface (API) memungkinkan untuk kustomisasi lengkap.

Proses instalasi LIFA dan firmware-nya ke papan Arduino uno harus diperhatikan [5]. Penggunaan VISA Labview dapat beroperasi dengan baik sangat dipengaruhi hardwarenya [6].

Seperti yang sudah disebutkan pada pendahuluan, optimasi program dibutuhkan pada penelitian ini karena kebutuhan pemrosesan yang cepat saat akuisisi data oleh pengendali utama. Karena salah satu subjek utamanya menggunakan Arduino Uno, maka penelitian ini menggunakan hasil penelitian sebelumnya yang berjudul "Pengaruh Struktur Pemrograman Dan Compiler Pada Kecepatan Operasi Menggunakan Arduino Uno" [2], sehingga dengan ini diharapkan proses akuisisi data lebih cepat.

Berdasarkan hasil riset sebelumnya [2], Arduino Uno memiliki kecepatan tertinggi untuk proses 1 Byte adalah 60ns, sehingga tidak mungkin bisa memproses lebih cepat dari yang paling sederhana ini.

Hasil penelitian ini menyatakan ada 2 cara mengoptimalkan kecepatan proses, pertama dengan cara mengatur struktur pemrogramannya, kedua dengan cara mengunakan level option compiler standar GCC Compiler dengan sintaks sbb.:

\#pragma GCC optimize ("-O3”)

Dengan cara ini, jika menggunakan level option ke-3 atau ("-O3") maka dapat mempercepat waktu proses hingga $78.23 \%$ dibandingkan standar compiler [2].

\section{Metodologi Penelitian}

Penelitian ini menggunakan Kuantiatif true experimental dengan fokus pretest-control group design. Penggunaan metodologi true-experimental karena dalam pelaksanaan penelitian ini dapat mengontrol semua variable luar yang mempengaruhi jalannya experimen, dengan demikian validitas internal dapat menjadi lebih tinggi. Dan focus pada metodologi pretest-control group design karena awal penelitian melakukan pengujian beberapa variable pengukuran pada berbagai modulnya sebelum 
diintegrasikan, sehingga dapat memudahkan saat penggabungan seluruh sistem.

Tahapan penelitian ini dimulai dari studi literatur, penentuan fokus Masalah penelitian, penetapan Tujuan penelitian sebagai solusi masalah, melakukan Pengujian, Analisa data lalu diakhiri kesimpulan.

Tolak ukur pengujian dijelaskan pada indikator kinerja penelitian dalam gambar tahapan rencana penelitian dan indikator kinerjanya. Untuk penyusunan referensi dan sitasi atau dan daftar pustaka menggunakan standard IEEE (2006) pada Microsoft Office Word 2013.

Untuk mencapai tujuan penelitian, dimulai dengan mengurutkan tahapan penelitian dan indikator kinerja yang disusun pada Gambar 1, dan masingmasing pengujian ini dilakukan di berbagai modul.

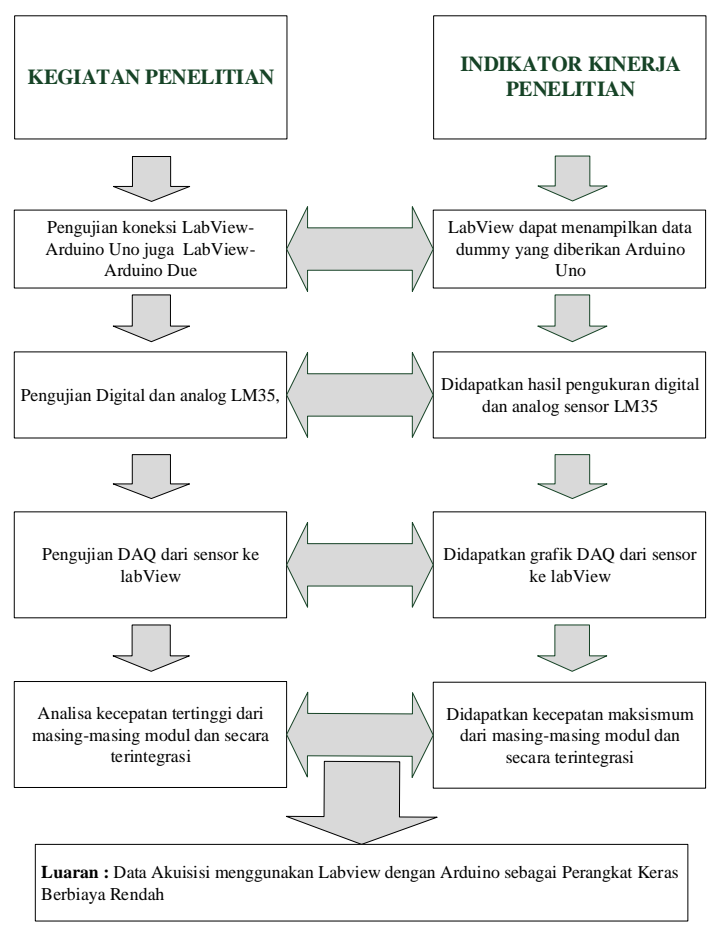

Gambar 1. Tahapan rencana penelitian dan indikator kinerjanya.

Tahap penelitian dimulai dengan menyiapkan seluruh komponen elektronik dan beberapa peralatan pengujiannya. Dimulai dari hardware sampai software ini seperti yang tertulis pada ruang lingkup pada bab pendahuluan.

Waktu penelitian akan banyak digunakan pada pengujian waktu tercepat perbagian dari akusisi data digital dan analog (LM35), pengujian waktu tercepat DAQ terintegrasi dari inputan ke labView, analisis data perbandingan.

Dengan begitu kita dapat menjawab tujuan dari penelitan ini, mengetahui kecepatan maksimal dari akuisi data Labview menggunakan Arduino sebagai perangkat kerasnya, sehingga pengguna dapat mengetahui batasan maksimal dari perangkat keras ini untuk keperluan data akuisi dengan LabView di laboratoruim maupun industri.

\section{Diagram Blok Produk Penelitian}

Produk penelitian ini terdiri dari beberapa blok, ini seperti yang ditunjukan oleh Gambar 2.

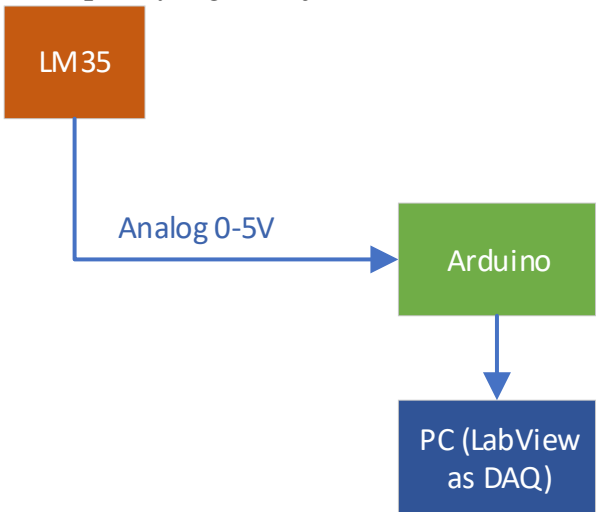

Gambar 2. Diagram Blok Sistem Keseluruhan

Dari gambar diatas terlihat bahwa sistem ini terdiri dari 3 Blok utama yaitu:

- LM35 adalah sensor suhu yang mewakili pembacaan data analog [7].

- Arduino sebagai perangkat keras akusisi data yang terhubung dengan LabView, Arduino yang diuji yaitu tipe Uno.

- PC sebagai penyimpan dan penampil data menggunakan labview.

\section{HASIL DAN PEMBAHASAN \\ Penggunaan LINX Markerhub}

Linx merupakan freeware dari markerhub, ini merupakan pengembangan dari Lvifa base. Linx bisa mendukung hardware lain selain arduino diantaranya: Arduino, Diligent, PJRC dan Sparkfun. Namun tidak semua tipe hardware Arduino dapat di akses secara mudah, beberapa hardware arduino yang dapat diakses dengan mudah sebagai sebagai hardware interface diantaranya: Leonardo, Mega2560, Nano, Pro Micro dan Uno. Gambar 3 merupakan tampilan window Wizard dari Linx untuk mengubah hardwarehardware tadi menjadi hardware interface dengan mudah:

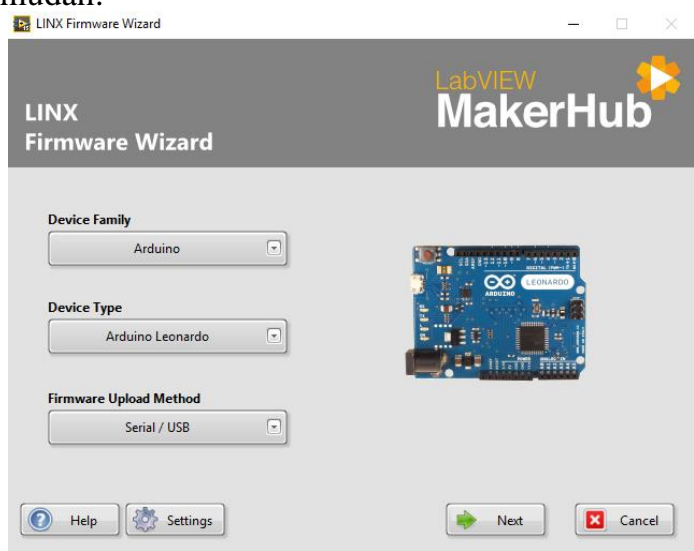

Gambar 3. LINX Firmware Wizard 


\section{Tahap Pengujian Referensi}

Pengujian ini dilakukan untuk mengkonfirmasi bahwa metoda pengukuran yang digunakan penulis sama dengan yang digunakan referensi utama. [4]

\section{Embedded fastest flip-flop}

Berikut merupakan pengujian fastest FlipFlop pada internal Arduino Uno berdasarkan referensi utama. Hasil pengujian ditunjukkan pada Gambar 4.
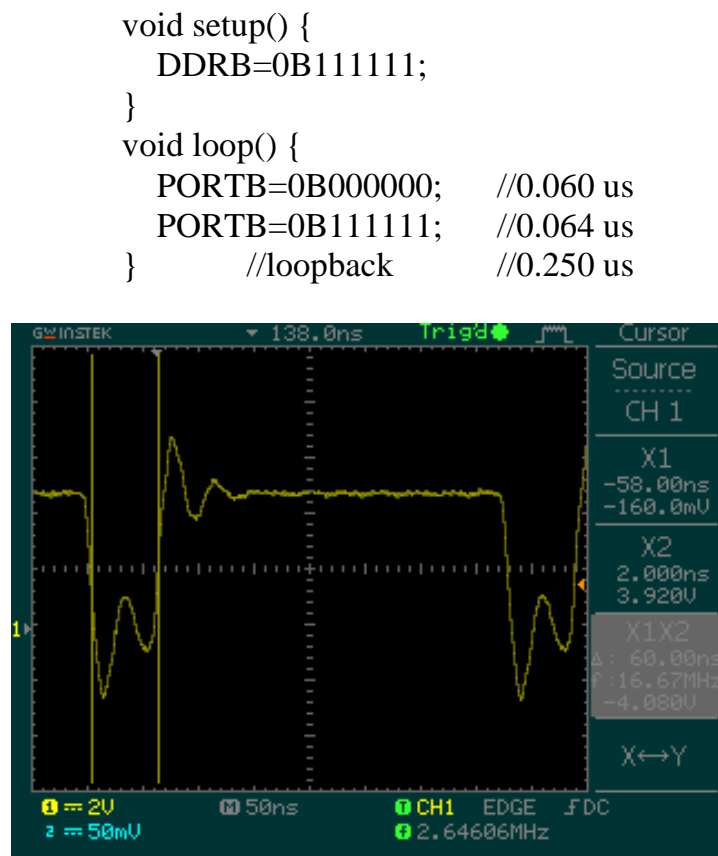

Gambar 4. Pengukuran flip-flop tercepat dari referensi utama

Selanjutnya dilakukan perhitungan waktu tempuh keseluruhan code jika prosedur diawali perintah Low, seperti pada script berikut ini.
LOW code $\quad: \mathbf{0 . 0 6 0}$ us
HIGH code : $\mathbf{0 . 0 6 4}$ us
Loopback code : $\mathbf{0 . 2 5 0}$ us

Signal High = HIGH code + Loopback code

$$
=0.064+0.250
$$

$$
=0.314 \mathrm{us}
$$

Metode ini kembali digunakan untuk melakukan pengujian waktu tempuh proses mengirimkan data yang ditandai dengan lamanya logic low yang di kompensasi dengan pengurangan LOW code, ini diukur menggunakan Osiloscope External pada PIN OUTPUT 8 pada Arduino Uno.

\section{Pengujian waktu tempuh proses mengirimkan data}

Pengujian dilakukan dengan cara mengirimkan 1 sampai 5 karakter agar pengukuran lebih objektif, tiap karakter berukuran 1 byte dari nilai ascii 8 bit. Berikut merupakan code pengujian yang dilakukan. void $\operatorname{setup}()\{$

DDRB $=0 \mathrm{~B} 111111$;

Serial.begin(250000);

\}

void $\operatorname{loop}()\{$

$$
\begin{aligned}
& \text { PORTB=0B000000; } / / \mathbf{0 . 0 6 0} \text { us } \\
& \text { //area code sama yang diukur //?????? } \\
& \text { PORTB=0B111111; //0.064 us } \\
& \text { //area code sama yang diukur //?????? } \\
& \text { //loopback }
\end{aligned}
$$

Pengujian code operation time dilakukan dengan cara membaca freq flipflop yang dibaca. Gambar 5 merupakan hasil pembacaan pengiriman serial 1 karakter dan rincian perhitungannya.

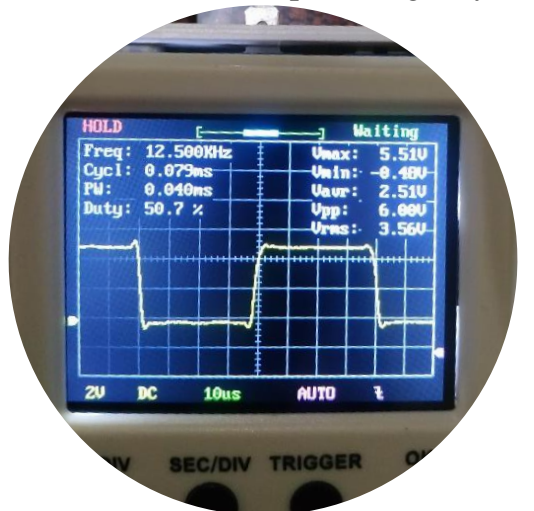

Gambar 5. Pengukuran double serial code dengan fast flipflop

Karena tiap loop, Frekuensi Pengukuran serial 1 karakter $=12,5 \mathrm{KHz}$ dan Waktu Double Code Pengiriman serial 1 karakter $=1 / 12,5.103=80$ us. Sehingga Total 1 loop time

$=$ LOW code + HIGH code + Loopback code

$=0,060+0,064+0,250$

$=0,374 \mathrm{us}$

Dengan demikian Presentase $=100.0,374 / 80=$ $0,47 \%$.

Oleh karena itu untuk mempercepat pengolahan penelitian, kompensasi waktu pengurangan fast flip-flop saat pengujian bisa diabaikan karena pengaruhnya hanya $0,47 \%$. Hasil pengujian ini ditunjukkan pada Tabel 2 Tabel 3.

Penambahan 40 us tiap karakter pada baudrate dalam perintah Serial.println() sama dengan pengiriman 2 karakter. Maka dapat disimpulkan metoda penelitian ini dengan yang digunakan pada referensi utama adalah identik dan dapat dibandingkan secara objektif. Hasil pengujian dalam pengiriman dengan baudrate 2 Mbps ditunjukkan pada Tabel 4. 
Tabel 2. Pengiriman dengan baudrate $250000 \mathrm{bps}$

\begin{tabular}{clccc}
\hline No & \multicolumn{1}{c}{ Double code test } & Freq $(\mathbf{H z})$ & Periode (us) & 1 Code (us) \\
\hline $\mathbf{1}$ & Serial.print(""); & 123408 & 8,10 & 4,05 \\
$\mathbf{2}$ & Serial.print("A"); & 12500 & 80,00 & 40,00 \\
$\mathbf{3}$ & Serial.print("AB"); & 6250 & 160,00 & 80,00 \\
$\mathbf{4}$ & Serial.print("ABC"); & 4166 & 240,04 & 120,02 \\
$\mathbf{5}$ & Serial.print("ABCD"); & 3121 & 320,41 & 160,21 \\
$\mathbf{6}$ & Serial.print("ABCDE"); & 2500 & 400,00 & 200,00 \\
$\mathbf{7}$ & Serial.println(); & 6250 & 160,00 & 80,00 \\
\hline
\end{tabular}

Tabel 3. Pengiriman dengan baudrate 250000 bps berbanding referensi utama

\begin{tabular}{clcccc} 
No. & \multicolumn{1}{c}{ Double code test } & Ref & error & error (\%) & Delta/Char \\
\hline $\mathbf{1}$ & Serial.print(""); & - & - & - & - \\
$\mathbf{2}$ & Serial.print("A"); & 30,34 & 9,66 & 75,85 & 35,95 \\
$\mathbf{3}$ & Serial.print("AB"); & 69,94 & 10,06 & 87,43 & 40,00 \\
$\mathbf{4}$ & Serial.print("ABC"); & 109,94 & 10,08 & 91,60 & 40,02 \\
$\mathbf{5}$ & Serial.print("ABCD"); & - & - & - & 40,19 \\
$\mathbf{6}$ & Serial.print("ABCDE"); & - & - & - & 39,79 \\
$\mathbf{7}$ & Serial.println(); & 69,94 & 10,06 & 87,43 & - \\
\hline
\end{tabular}

Tabel 4. Pengiriman Serial pada baudrate $2 \mathrm{Mbps}$

\begin{tabular}{clcccc}
\hline No. & \multicolumn{1}{c}{ Double code test } & Freq (KHz) & Periode (us) & 1 Code (us) & Time / Char \\
\hline $\mathbf{1}$ & Serial.print(""); & 123,4 & 8,10 & 4,05 & - \\
$\mathbf{2}$ & Serial.print("A"); & 49,85 & 20,06 & 10,03 & 5,98 \\
$\mathbf{3}$ & Serial.print("AB"); & 31,25 & 32,00 & 16,00 & 5,97 \\
$\mathbf{4}$ & Serial.print("ABC"); & 22,75 & 43,96 & 21,98 & 5,98 \\
$\mathbf{5}$ & Serial.print("ABCD"); & 17,89 & 55,89 & 27,95 & 5,97 \\
$\mathbf{6}$ & Serial.print("ABCDE"); & 14,73 & 67,87 & 33,94 & 5,99 \\
$\mathbf{7}$ & Serial.println(); & 31,25 & 32,00 & 16,00 & - \\
\hline
\end{tabular}

Dari Tabel 4 didapatkan bahwa dalam waktu pengiriman serial tercepat adalah 1 karakter, dengan waktu rata-rata yaitu 5,98 us untuk setiap Byte-nya pada kecepatan baudrate 2Mbps. Gambar 6 merupakan hasil dari pembacaan pengiriman serial 1 karekter pada baudrate $2 \mathrm{Mbps}$ :

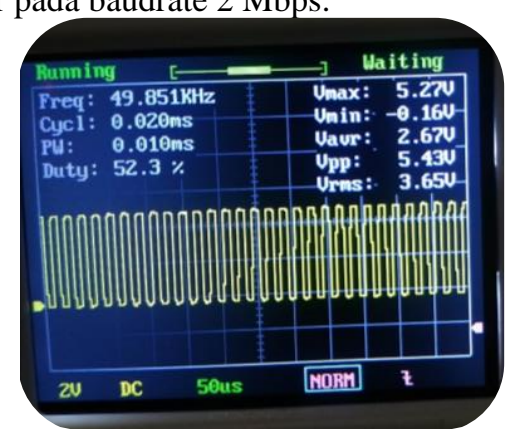

Gambar 6. Frekuensi serial 1 karakter pada baudrate 2 Mbps
Pengujian labview, arduino dan linx

Pada tahap ini, pengujian dilaksanakan berdasarkan diagram blok yang ditunjukkan pada Gambar 7, sedangkan tampilan front panel linx-blynk ditunjukkan pada Gambar 8.

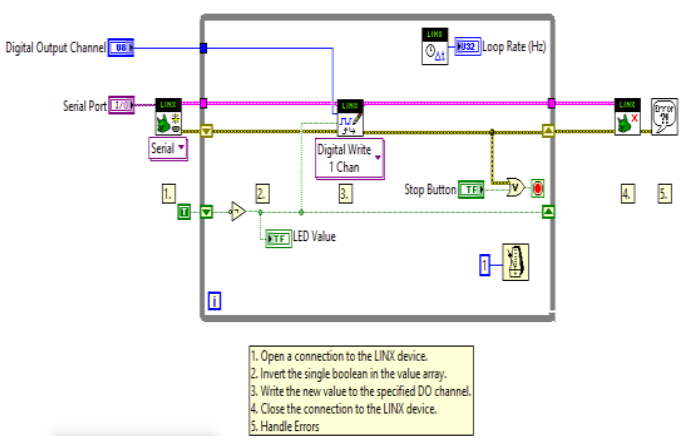

Gambar 7. Blok Diagram LINX - Blink (Advance) example code 


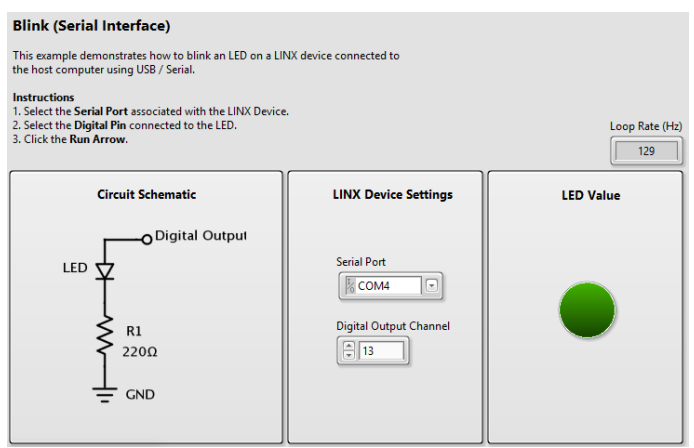

Gambar 8. Front Panel LINX - Blink (Advance) example code

Pada Linx disediakan fitur pembacaan freq loop pengulangan pada sistem Akuisi data. Salahsatu example code dari linx adalah "LINX - Blink (Advance)". Blok diagram dan Fontpanel-nya ditunjukan pada gambar 7 dan 8 diatas.

\section{Pengujian akuisisi data digital 2 arah (Triger- Echo)}

Bagian ini melakukan pengujian kecepatan komunikasi 2 arah tercepat dan tersederhana dari akusisi data menggunakan Labview, Arduino dan Linx. Diawali dengan menghubung-singkatkan Pin 12 dan 13 pada Arduino Uno dan menghubungkan kabel USB-nya pada PC. Persiapan perangkat keras dalam pengujian ditunjukkan pada Gambar 9.

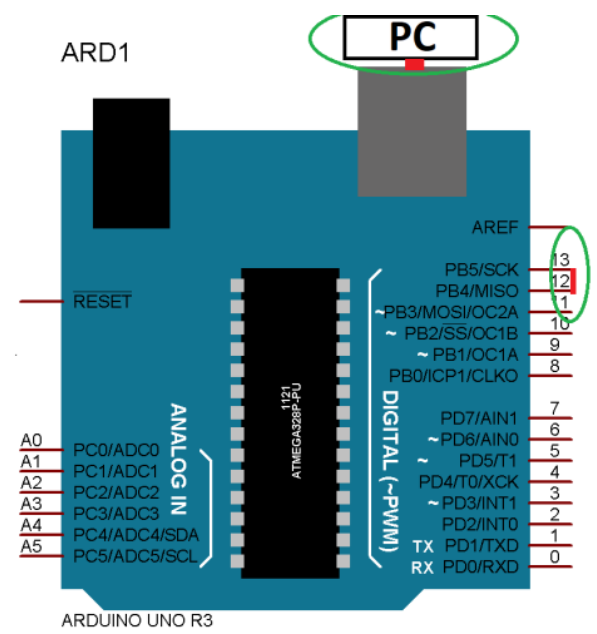

Gambar 9. Persiapan HW pengujian akuisisi Digital (Triger-Echo)

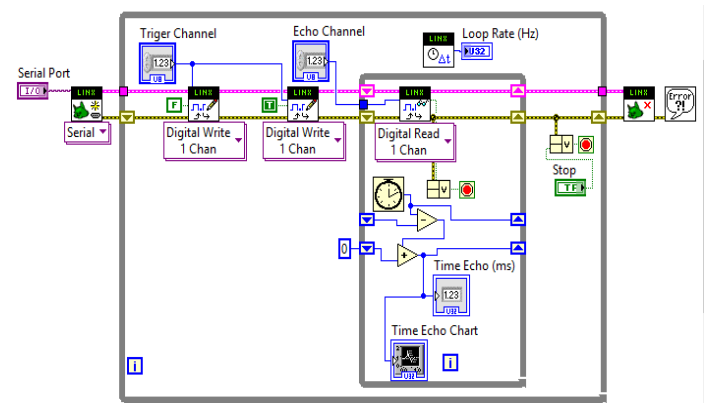

Gambar 10. Blok diagram Triger-Echo digital test

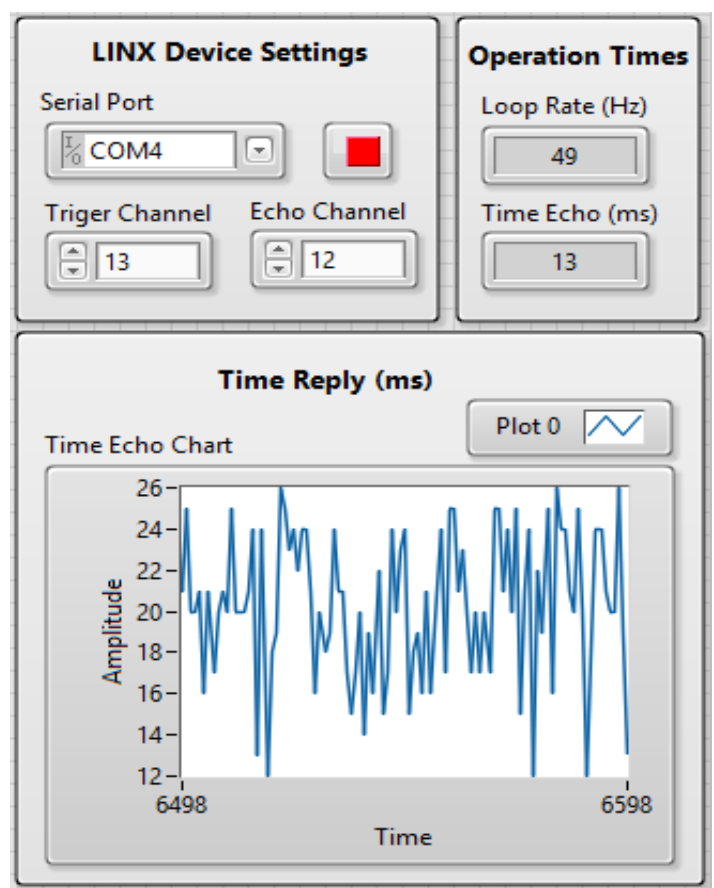

Gambar 11. Front panel Triger-Echo digital test

Blok diagram dan Front panel pada labview yang dibuat ditunjukan pada Gambar 10 dan Gambar 11. Hasil pengamatan pada oskiloskop ditunjukkan pada Gambar 12.

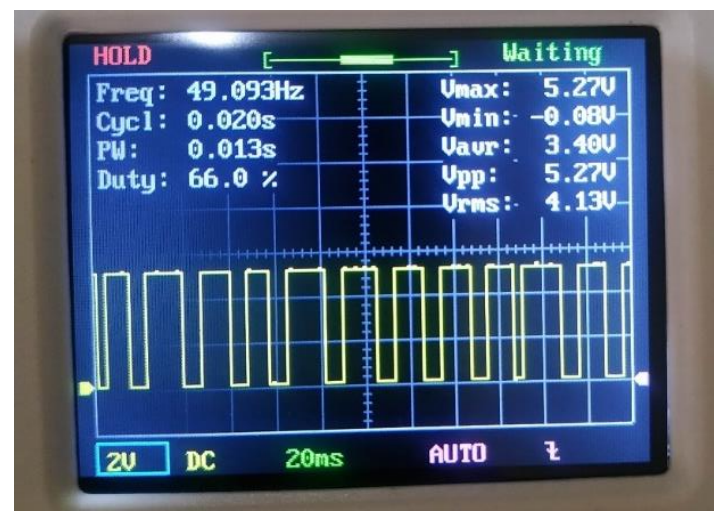

Gambar 12. Frekuensi pengujian akuisisi Digital 2 arah (Triger-Echo)

Osiloskop diatas dihubungkan pada pin 13 yang men-trigger pin 12 Arduino Uno, hasil pembacaan frekuensinya sama dengan yang tertampil pada Front panel Labview. Maka dapat disimpulkan hasil pengukuran menggunakan "loop rate" ini valid diangap sebagai pengukuran waktu 2 arah (triggerecho), karena angka ini identik sama dengan yang tertampil pada Osiloskop ekternal.

$$
\begin{array}{ll}
\mathrm{F} \text { Loop rate AVG } & =49 \mathrm{~Hz} \\
\mathrm{~T} / \text { loop time AVG } & =1 / 49 \\
& =20.41 \mathrm{~ms}
\end{array}
$$

Pengujian Akuisisi digital 2 arah dengan cara (trigger-echo) adalah $20.41 \mathrm{~ms}$ untuk lintasan bulak balik dari PC ke Arduino Uno hingga kembali ke PC. 
berlaku pada sensor dengan kemampuan waktu pengiriman data dibawah $20.41 \mathrm{~ms}$.

\section{Pengujian pengiriman data digital 1 arah (fastest flip-flop)}

Bagian ini merupakan pengujian kecepatan komunikasi paling sederhana, yaitu pengiriman data digital 1 arah menggunakan Labview, Linx dan Arduino. Blok diagram dan Front panel pada labview ditunjukkan pada Gambar 13 dan Gambar 14.

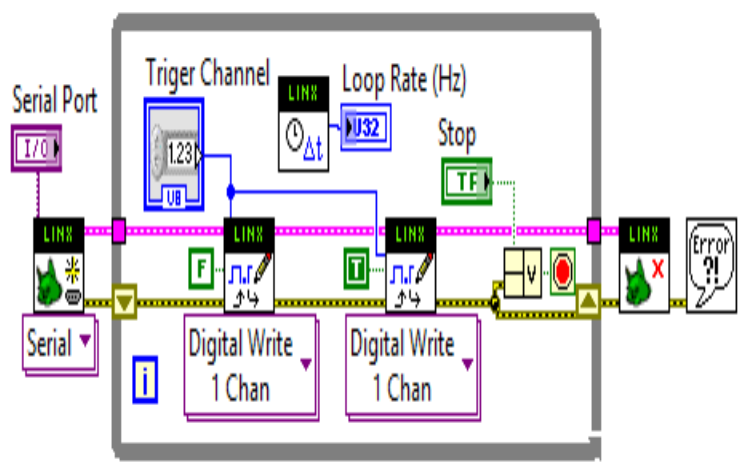

Gambar 13. Blok diagram Pengiriman data Digital 1 arah (flip-flop)

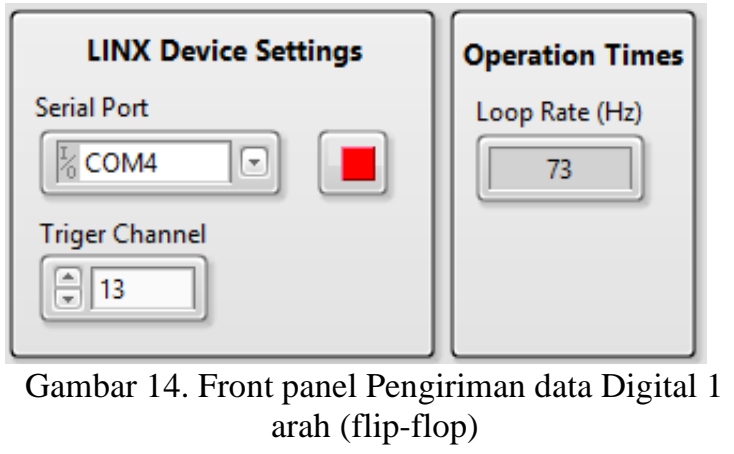

Dari hasil pembacaan didapatkan bahwa Pengiriman data Digital 1 arah (fastest flip-flop), menghasilkan Frekuensi $=73 \mathrm{~Hz}$, artinya perioda $13,7 \mathrm{~ms}$.

\section{Pengujian akuisisi data analog (LM35)}

Bagian ini merupakan pengujian akuisi data analog yang diwakilkan oleh senor suhu LM35. Blok diagram dan Front panel yang dibuat ditunjukan pada Gambar 15 dan Gambar 16.

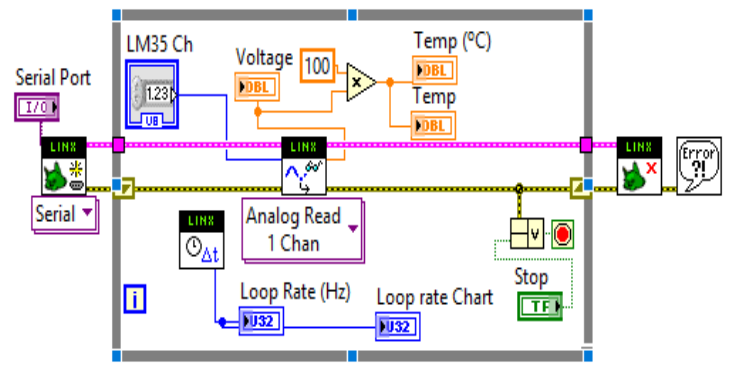

Gambar 15. Blok Diagram Pengujian Analog (LM35)

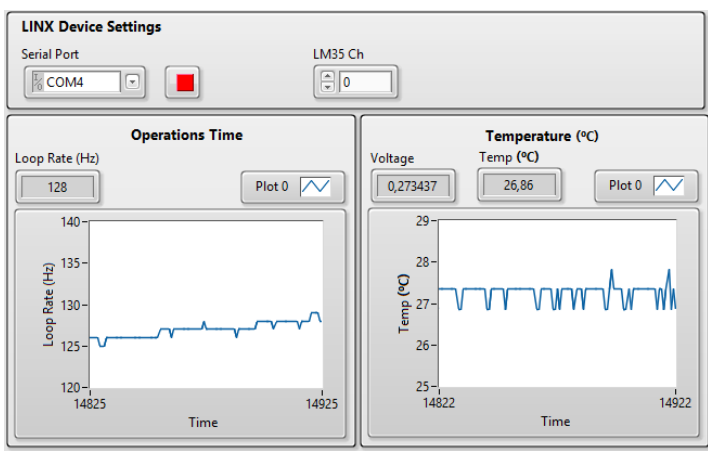

Gambar 16. Front panel Pengujian Analog (LM35)

Dari hasil pengujian dapat dilihat bahwa pembacaan analog memiliki AVG Loop rate $127 \mathrm{~Hz}$ atau menggunakan waktu rata-rata $7.87 \mathrm{~ms}$ pada setiap loopnya.

\section{KESIMPULAN \\ Kesimpulan}

Tanpa menggunakan Linx firmware wizard, kecepatan tertinggi arduino uno mengirimkan sinyal serial 1 karakter, rata-rata waktu tempuh setiap Bytenya yaitu 5,98 us pada kecepatan baudrate $2 \mathrm{Mbps}$. Pengukuran menggunakan "loop rate $(\mathrm{Hz})$ " ini valid diangap sebagai pengukuran waktu 2 arah (triggerecho), berlaku pada sensor dengan kemampuan waktu pengiriman data dibawah $20.41 \mathrm{~ms}$. Akuisisi digital 2 arah dengan cara (trigger-echo) adalah $20.41 \mathrm{~ms}$ untuk lintasan 2 arah dari PC ke Arduino Uno hingga kembali ke PC. Pengiriman data Digital 1 arah (flipflop) memiliki waktu rata-rata $13,7 \mathrm{~ms}$ pada setiap loopnya. Pengujian akuisisi data analog menggunakan LM35 memiliki waktu rata-rata 7.87 ms pada setiap loopnya.

\section{Saran}

Penelitian ini tentunya banyak kekurangan, untuk menyempurnakan penelitian ini dapat dilanjutkan pada beberapa hal berikut:

- Membuat cassing (fabrikasi) agar produk ini lebih aman dan kokoh saat digunakan praktikum di laboratorium bahkan dapat digunakan di industri.

- Pengujian selanjutnya dilakukan akuisis data pada skala yang lebih besar dan waktu pengujian yang lebih lama, agar lebih mendekati industri pada umumnya.

\section{UCAPAN TERIMA KASIH}

Alhamdulillah kami ucapkan karena atas karena ridho-Nya penelitian ini dapat dimulai dan diselesaikan. Juga kami ucapkan banyak terima kasih kepada;

- Dr. Ir. Noor Cholis Basjaruddin, MT. selaku Kepala UPPM Politeknik Negeri Bandung yang memberikan kesempatan untuk mendanai penelitian ini. 
- Para Reviewer POLBAN dan Jurnal GEMA Teknologi yang memberikan banyak saran dan masukan yang bermanfaat.

- Pihak lain yang tidak bisa disebutkan satupersatu yang telah banyak membantu hingga penelitian ini selesai.

\section{DAFTAR PUSTAKA}

1. K. Sammy, 2014, LINX, LIFA \& Arduino, Markerhub, 291 2014. [Online]. Available: https://forums.ni.com/t5/LabVIEW-Interfacefor-Arduino/LINX-LIFA-Arduino/td$\mathrm{p} / 3372499$ ? profile.language $=\mathrm{en}$. [Accessed 10 7 2019].

2. D. N. Bagenda and R. Hudaya, 2016, Pengaruh Struktur Pemrograman Dan Compiler Pada Kecepatan Operasi Menggunakan Arduino Uno, in SNTEI - Seminar National Teknik Elektro Dan Informatika, Makassar.

3. N. R and P. Krishna, 2013, Low Cost Data Acquisition and Control using Arduino Prototyping Platform and LabVIEW, International Journal of Science and Research
(IJSR), , vol. 2, no. 2, pp. 366-369, February 2013 .

4. N. Kanani and M. Thakker, 2015, Low Cost Data Acquisition System Using LABVIEW, 2nd International Conference on Multidisciplinary Research \& Practice (IJRSI), vol. 3, no. 1, pp. 67-70.

5. A. E. Hammoumi, S. Motahhir, A. Chalh, A. El Ghzizal and A. Derouich, 2018, Real-time virtual instrumentation of Arduino and LabVIEW based PVpanel characteristics, A ElHammoumi, vol. 161, no. 1, pp. 1-12.

6. E. V. Beauchamp and E. Lozano, 2014, Comparing USB Data Acquisition Instruments Using Arduino and PIC18F4550 in LabVIEW and Matlab, International Journal Of Innovative Research In Electrical, Electronics, Instrumentation And Control Engineering, Vol. 2, No. 9, pp.1952-1958.

7. Texas Instruments, 2017, LM35 Precision Centigrade Temperature Sensors, SNIS159H August 1999 - Revised December 2017. 